\title{
Destination Image and Perceived Risk of Visiting Ukraine: An Exploratory Study of Chinese Male Outbound Tourists
}

\author{
Jun Wen ${ }^{1, *}$, Dr. Tim Lockyer ${ }^{1}$, Hanlin Zhang ${ }^{1}$ \\ ${ }^{I}$ Department of Tourism and Hospitality Management, Waikato Management School, University of Waikato, \\ Hamilton, New Zealand
}

*Corresponding Author: Jun Wen, Department of Tourism and Hospitality Management, Waikato Management School, University of Waikato, Hamilton, New Zealand

\begin{abstract}
Despite increasing research in destination image, few attempts have been made to explore the link between destination image and perceived risk. This paper addresses this significant gap in the literature. The paper examines the aforementioned concepts by exploring Chinese tourists visiting Ukraine. Due to the country's 2013 crisis, political instability is still notable there. The paper conducted 17 in-depth interviews with Chinese respondents who visited Ukraine. While television news and Internet provide the main sources of information, it was found that these tourists had limited knowledge about Ukraine prior to their visit. In terms of destination image, the most important attributes relating to Ukraine for Chinese tourists were its being a risky country and the beauty of Ukrainian women. The two main perceived risks of visiting Ukraine are political instability and language barrier. Some respondents, however, argued that the perceived risk actually increased their willingness to visit Ukraine.
\end{abstract}

Keywords: Destination Image, Perceived Risk, Chinese Outbound Tourists, Ukraine

\section{INTRODUCTION}

The dramatic growth of the international tourism market has played an important role in economic development recently. According to Statista (2016), the number of international tourist arrivals reached 1.09 billion by the end of 2014, contributing US\$7.17 trillion to the global economy. By 2030, international tourist arrivals are expected to exceed 1.8 billion. In terms of international tourist expenditure, the rapid development of the international tourist market has created US\$1159 billion global international tourism revenue. Despite its economic significance, the tourism industry is highly vulnerable to natural and human-caused disasters and crisis events (Faulkner, 2001). Political instability as one of the most common forms of crisis events has been widely examined by recent studies (Causevic\& Lynch, 2013; Steiner, 2007; Yap \&Saha, 2013). According to Hall and O'Sullivan's (1996) working definition, political instability is usually understood as a condition under which political legitimacy, social order, and governance are challenged. Though the adverse effects of political instability have been identified, a review of the literature reveals that there is a notable lack of understanding of tourists' perceptions of political instability. To fill this gap in the literature, this study attempts to examine Chinese outbound tourists' perceptions of political instability in Ukraine. In so doing, special attention was given to destination image and the perceived risk of visiting Ukraine.

Ukraine has suffered from political instability as a result of the Ukraine crisis and the Autonomous Republic of Crimea's entry into the Russian Federation. International tourist numbers to Ukraine have experienced a steep drop due to this political instability, falling from 24.7 million in 2013 to 12.4 million in 2015 (Visit Kiev Ukraine, 2013). Given that the tourism industry provides crucial support for Ukraine's economy, the country is facing financial difficulties due to its shrinking inbound tourism market. In order to restore its inbound tourism market and promote economic development, the Ukrainian government is taking measures to attract more foreign visitors. Given fast-growing Chinese outbound tourist numbers and tourist expenditure, the Ukrainian government is attempting to attract more Chinese outbound tourists. For example, between 20 June and 30 September 2016, Chinese citizens can obtain a visa on arrival at Boryspil International Airport that allows them to stay for up to 15 days (Xinhua, 2016). Given the close link between destination image and behavioural 
intentions identified by Chen and Tsai (2007), it is extremely important for Ukraine tourism marketers to understand Chinese outbound tourists' perceived image of Ukraine in order to better market the country and to service these tourists. As the conflict in the east of Ukraine is still ongoing, visiting Ukraine is possibly more risky than visiting other Eastern European countries. Thus, it is important to ask: How do Chinese tourists perceive the risk of visiting a politically unstable Ukraine? The purpose of this study is, therefore, twofold: 1) to identify Chinese tourists' destination image of Ukraine, and 2) to identify Chinese tourists' perceived risk of visiting Ukraine.

\section{LITERATURE REVIEW}

\subsection{Destination Image}

Destination image is generally defined as "the sum of beliefs, ideas and impressions that a person has of a destination" among the different definitional constructions (Crompton, 1979, p. 18). Destination image is found to be a critical factor influencing tourists' selection of tourism destinations (Chen \& Tsai, 2007). Given the significance of destination image for tourism marketers, various studies have focused on the factors influencing the destination image formation process to better manage destination image (Baloglu\&McCleary, 1999; Beerli\& Martin, 2004). The two primary components of the destination image identified by tourism scholars are cognitive image and affective image (Crompton, 1979). Cognitive image refers to tourists' beliefs about the destination attributes, while affective image refers to tourists' feelings toward the destination (Berrli\& Martin, 2004). Though destination image is a complex phenomenon, the majority of destination image studies have focused on the cognitive image (Pike \& Ryan, 2004). According to Engel, Blackwell, and Miniard (1986), image is the consumer's subjective perceptions, which refer to how an alternative performs on important evaluative criteria. Baloglu and McCleary (1999) further argued that cognitive image is also influenced by environmental and psychological elements. However, Russell and Snodgrass (1987, p. 246) argued that "behaviour may be influenced by the (estimated, perceived, or remembered) affective quality of an environment rather than by its objective properties directly." There are three types of affective destination images: favourable, unfavourable, and neutral. Gartner (1993) suggested that the components of affective destination image are important for evaluating different travel alternatives. Furthermore, emotion was found to be an important indicator when evaluating affective destination image (Yu \& Dean, 2001). Despite its obvious significance, affective destination image is underresearched. According to Pike (2002), only 6 out of 142 previous studies examined affective destination image. However, Baloglu and McCleary (1999) have argued that the two-dimensional approach (cognitive image and affective image) makes it possible to overlook the overall evaluation of a destination. Consequently, some tourism scholars have attempted to propose a third construct of destination image. For example, in order to have a comprehensive understanding of destination image, Baloglu and McCleary (1999) proposed overall image as the third component of destination image. Moreover, scholars such as Gartner (1993), and Pike and Ryan (2004) have proposed conative destination image as a third element in the destination image construct. The conation dimension reflects a likelihood of destination selection, or brand purchase, and can be interpreted as a propensity to visit a destination within a certain time frame (Pike \& Ryan, 2004). In fact, both the cognitive and affective components of destination image influence the conative elements of destination image. According to Baloglu (2001), the conative components of destination image play an important role in segmenting and targeting potential tourists.

\subsection{Perceived Risk}

Perceived risk has been widely examined by existing tourism studies (Lepp\& Gibson, 2003; Lepp, Gibson, \& Lane, 2011). According to Sönmez and Graefe (1998), for instance, the increasing number of crisis events such as terrorism, political instability and crime has raised awareness of understanding tourists' perceptions of risk associated with a tourism destination. As Sirakaya, Sheppard, and McLellan (1997, p. 2) prophesised, "the security and safety concerns of potential tourists can create serious management problems which can have long-lasting, disastrous economic effects on host communities if those concerns cannot be forecasted, planned, controlled and properly managed." They further pointed out that a safe destination image leads to a higher likelihood of visitation, while a risky destination image leads to lower likelihood to visit. Their finding was supported by Sönmez and Graefe (1998) who found that perceived risk was a strong predictor of avoiding visiting a 
particular destination. For example, tourists who perceive terrorism as a risky activity may be unlikely to visit the Middle East. Therefore, countries which are perceived as risky need to understand and manage tourists' perceptions of risk. Previous studies have identified a variety of factors which influence perceived risk. For example, Roehl and Fesenmaier (1992) identified seven factors influencing perceived risk; they include equipment, financial factors, physical factors, health factors, satisfaction, social factors, and time. Sönmez and Graefe (1998) extended this list and proposed three additional risk factors: health, political instability, and terrorism. Furthermore, Reisinger and Mavondo (2005) examined tourists' perceptions of risk related to sociocultural differences. Lepp and Gibson (2003) used Cohen's (1972) typology to examine perceptions of risk associated with seven factors: political instability, terrorism, health, strange food, cultural differences, the political and religious dogma of a country, and crime. Lepp and Gibson (2008) later found that tourists' perceptions of risk are related to specific regions of the world.

Previous studies have also identified the link between tourists' characteristics and perceived risk. Roehl and Fesenmaier's (1992) study identified three groups of tourists based on their perceptions of risk; these included risk neutral, functional risk, and place risk. The risk neutral group believed that tourism, or their selected destination, was not risky at all. The functional risk group thought tourism, or their selected destination, might contain risky factors. The possibility of mechanical, equipment, or organisational problems were regarded as the main sources of tourism-related risk. The place risk group tends to perceive the holiday destination as a fairly risky place. The risk neutral group tends to be able to frame risk as part of the excitement of tourism. Lepp and Gibson (2003) also proposed that tourists' perceptions of risk associated with international tourism are influenced by previous travel experience, age, gender, and nationality. In terms of previous travel experience, it was found that novelty seekers were more likely to visit risky destinations than familiarity seekers (Lepp\& Gibson, 2008). In terms of age, Gibson and Yiannakis (2002) found that tourists' preference for risk-related tourism tended to decrease with age. In terms of gender, Lepp and Gibson (2003) found that female tourists tended to perceive greater risks related to health and food. Carr (2001) found that female tourists associated being in cities at night with greater perceived risk. Qi, Gibson, and Zhang (2009) found that women perceived more risk associated with violence in China. Pizam et al. (2004) found that males are more likely than females to select riskier types of vacations. By examining tourists from six Western European countries, Seddighi, Nuttall, and Theocharous (2001) demonstrated that levels of perceived risk associated with international tourism vary by nationality.

\section{RESEARCH METHODS}

Given the limitations of quantitative research methods and the exploratory nature of this study, semistructured interviews were adopted as the most appropriate methodology to achieve the purposes of this research for three reasons. First, little information about Chinese tourists to Ukraine was actually found in the literature; consequently, it was hard to design suitable questionnaire items. Unlike questionnaire surveys, interviews are a way to find out what is on the researched respondent's mind (Patton, 1990). Secondly, semistructured interviews enable the researcher to facilitate both the interaction and the depth of discussion on the research topic (Sandiford\& Seymour, 2007). Moreover, semistructured interviews offer flexibility by allowing interviews to be fluid in nature and to follow the thinking process of the Chinese tourist respondents' perceived image of Ukraine and their perceived risk of visiting Ukraine within the framework of the research objectives.

The first author of this paper conducted the study's interviews between 1 July 2016 and 13 July 2016. All respondents were clients of Chinese travel agencies providing tours to Ukraine. Purposive sampling was employed to recruit participants for this study. The researcher initially contacted the potential respondents using email and mobile phone information provided by the agencies. Subsequently, the researcher first introduced himself and then the research project and its purpose to potential respondents. Informing respondents that all data would be confidential was deemed the most effective way to secure potential respondents willing to participate in this research. A total of 17 respondents participated in the telephone interviews voluntarily. The interviews were recorded and each lasted between 30 and 45 minutes. The interview questions covered two broad themes relevant to the research objectives, namely, the participants' perceived destination image of Ukraine, and the perceived risk of visiting Ukraine. The data were translated into English at the transcription stage. The recordings and transcripts were checked by a Chinese-English linguist to ensure the accuracy of the 
translation. The process of data analysis involved two stages. The first was to become familiar with the text through repeatedly reading the transcripts. The data were then manually coded and subjected to thematic analysis.

\section{RESEARCH OUTCOMES}

\subsection{Profile of Respondents}

Table 1 shows the respondents' profile. All the participants are males, aged from 25 to 36; they represent a variety of occupations such as civil servants, school teachers, bank staff, businessmen, doctors, and HR managers. All of the respondents who participated in this study stayed in Ukraine for 7 nights. All the respondents visited Ukraine on guided tours and so their 7-night stay represents the most popular types of Chinese tours Chinese tourists take to Ukraine.

Table1. Profile of Respondents

\begin{tabular}{|c|c|c|c|c|}
\hline Participant No. & Age & Gender & Occuptation & Nights in Ukraine \\
\hline 1 & 26 & Male & Unemployed & 7 \\
\hline 2 & 29 & Male & Businessman & 7 \\
\hline 3 & 36 & Male & Doctor & 7 \\
\hline 4 & 29 & Male & HR Manager & 7 \\
\hline 5 & 27 & Male & Computer Programmer & 7 \\
\hline 6 & 28 & Male & Freelancer & 7 \\
\hline 7 & 33 & Male & Civil Servant & 7 \\
\hline 8 & 32 & Male & Oftaff & 7 \\
\hline 9 & 25 & Male & Investment Company Staff & 7 \\
\hline 10 & 27 & Male & Journalist & 7 \\
\hline 11 & 28 & Male & Adminstrator & 7 \\
\hline 12 & 36 & Male & Civil Servant & 7 \\
\hline 13 & 35 & Male & School Teacher & 7 \\
\hline 14 & 32 & Male & Civil Servant & 7 \\
\hline 15 & 33 & Male & Civil Servant & \\
\hline 17 & 32 & Male & Project Manager & \\
\hline
\end{tabular}

\subsection{Sources of Information}

In order to gauge the respondents' knowledge of Ukraine, they were asked what they knew about Ukraine and how they had gained that knowledge. Nine of the 17 participants in this study stated that they had very little knowledge in relation to Ukraine prior their visit. They had just learned something related to the Ukraine crisis from the television news, Internet, blogs, and Wechat:

Ukraine is an unfamiliar country to me. I did not find any tourism-related information about it prior to my visit. I just got some tourism information from the tour guide prior to the visit (Participant 1).

When the Ukraine crisis happened, I started to hear something about this country on the television news. However, I still had got only limited knowledge about this country. From my perspective, the Ukraine crisis has helped more people across the world pay attention to this European country (Participant 2).

Four respondents argued that they did a lot of research prior their visit. They knew that there was a possibility that there could be a war in Ukraine and so they tried to ensure that Ukraine was still a safe destination for them prior to their visit. They searched online and contacted the Chinese Embassy in Ukraine prior their visit:

Honestly speaking, I did a lot of research about Ukraine before this trip. I read blogs written by tourists who had been to Ukraine before. I wanted to know more about this country, such as the food and tourist attractions. I also knew that the current political situation in Ukraine is unstable. Therefore, in order to make sure of the safety of visiting Ukraine, I also consulted the Chinese Embassy in Ukraine to figure out the current political situation of Ukraine. I did prepare a lot for this trip (Participant 17). 
Other respondents mentioned that they knew Ukraine from a very specific angle, mentioning the local women of Ukraine:

I read some profiles of beautiful Ukraine girls on the Internet and Wechat. The beautiful local women of Ukraine really attracted me to visit this country. They are described as tall, with a sexy body, good personality, easy-going, and friendly to Chinese, and some of them have married Chinese men (Participant 5).

In summary, the majority of Chinese tourists had minimal knowledge about Ukraine prior to visiting the country. Although four participants had undertaken in-depth research about Ukraine to make sure it was safe to visit, it was found that overall Ukraine is an unfamiliar outbound destination for Chinese outbound tourists, with their main sources of information coming from the Internet, blogs, Wechat, and tour operators.

\subsection{Chinese Tourists' Destination Image of Ukraine}

In order to explore Chinese outbound tourists' destination image of Ukraine, respondents were asked how they perceive Ukraine as a tourist destination. Not surprisingly, given its current political situation, Ukraine was perceived as a more risky destination compared to other European destinations:

Safety is a big concern for tourists. I think that some parts of Ukraine are still at war. Compared to other European countries such as England, France, and Germany, visiting Ukraine is more risky (Participant 7).

Nine respondents mentioned beautiful local women as one dimension of Ukraine's destination image. More importantly, some respondents regarded the possibility of having a romantic experience with local women as an important motivation for travelling to Ukraine. They also mentioned that this particular motivation arose from the complicated process of starting relationships between Chinese men and women in China's current society:

I knew about Ukraine and its local women from other travellers' blogs online. These other travellers usually remarked that Ukrainian women tend to be more easy-going and that they find it simpler to build a relationship with men than Chinese women do. Comparatively, Chinese women tend to be more materialistic when seeking a mate. In this sense, Ukrainian women left a good impression on these travellers who were seeking a simple and purely romantic relationship (Participant 12).

The reasons why Chinese outbound tourists perceived Ukrainian women as a strong motivation factor in Ukraine's destination's image is of noteworthy relevance to the research, in particular, because of the perceived ease of seeking a romantic relationship with a Ukrainian woman as opposed to a Chinese woman. On this topic, one respondent remarked:

In current Chinese society, Chinese women tend to seek mates who own properties, cars, and other luxury goods in order to secure a rich and stable life. This phenomenon results in an increasing number of Chinese women requiring more from men; hence, proper relationships are rarely found between Chinese people. However, the news Chinese men have married Ukrainian women has gradually been revealed to more Chinese people. Therefore, as I see it, social media have played an important role in making more Chinese people understand Ukraine, as well as Ukrainian women (Participant 13).

In summary, this study identifies two perceived destination images that draw Chinese tourists to Ukraine; these images include not only a perceived risk caused by political instability but also the allure of beautiful Ukrainian women which was found to be an important motivator for male Chinese tourists to Ukraine.

\subsection{Perceived Risk of Visiting Ukraine}

As discussed above, most of the participants perceived Ukraine as a riskier destination compared to other European outbound destinations. This finding confirms previous studies which support the idea that political instability increases the perceived risk of visiting tourist destinations:

There is no doubt that the Ukraine crisis hinders inbound tourism to Ukraine. Political instability in Ukraine increases the 'uncertainty' of visiting Ukraine. Tourists may be concerned about safety when visiting Ukraine (Participant 3). 
Another perceived risk mentioned by some respondents is the language barrier. English is not very important in Ukraine's educational system; therefore, some respondents argued that it might be hard for them to communicate with local people:

I know that the majority of Ukrainian people cannot speak English. I wanted to have more contact with local people, especially beautiful local women. However, that might be a problem for me due to the language barrier (Participant 8).

Despite political instability increasing the perceived risk of visiting Ukraine, some respondents mentioned that the Ukraine's crisis actually increased their willingness to visit the country:

I did not regard political instability as a risk issue for me to visit Ukraine. I regarded visiting

Ukraine as an adventure. It really increased my willingness to visit Ukraine (Participant 17).

Two respondents mentioned that as Ukraine could potentially find itself at war, the supply of sufficient daily necessities could be unstable during the war period. One respondent remarked:

As I know, human daily necessities such as food, water, petrol etc. are normally under government control or in shortage, which is a major potential risk, in particular, for foreign tourists. Therefore, just after I arrived in Ukraine, I spent half day buying enough food and water in case a bad situation might occur (Respondent 10).

\section{DISCUSSION AND CONCLUSION}

This study conducted 17 in-depth interviews with Chinese outbound tourists who had previously visited Ukraine in order to understand the destination image and perceived risk of travelling to Ukraine. As shown in Table 1, all 17 respondents involved in this study were randomly selected and all of them were male. The respondents' answers in relation to Ukraine's destination image show that they had limited knowledge regarding Ukraine as a whole; however, the attraction of Ukrainian local women could be regarded as one of the most important destination image factors, from Chinese male tourists' perspective. Furthermore, uncovering the important role of Ukrainian women in the process of Chinese male tourists' making their decision to visit Ukraine revealed the importance of that motivation.

As the respondents stated, they were strongly motivated to pursue the building up of a romantic relationship which was simple and pure and which was more focused on the 'relationship' itself rather than on the seeking of a mate with other attractions such as assets, properties, luxury cars, or consumption capability. Some respondents mentioned that some Chinese women have become materialistic because of the huge and consistent pressure from life and work. Consequently, finding 'Mr. Right' is no longer their first criterion when considering starting a new relationship. Some respondents had searched out information regarding Ukrainian women on issues such as their personality, lifestyle, and their perceptions of finding a mate. These Chinese male outbound tourists, therefore, possibly viewed travelling to Ukraine as a smart way to date the local women. In light of the limited destination images of Ukraine as a tourist destination, seeking romantic dates could, as a result, be regarded, from the perspective of male Chinese tourists, as one important motivation for visiting Ukraine.

The perceived risks of visiting a tourist destination are another important factor involved in the decision-making process of tourists. For Chinese tourists visiting Ukraine, especially in times of political instability and potential war, these factors are of great significance when it comes to understanding these tourists' behaviours. Obviously, most of the study's respondents were concerned about the potential for war in Ukraine, and they mentioned that they had made some preparations for this eventuality. By undertaking prior research on their destination, the Chinese tourists showed how they offset potential risks. From the perspective of Chinese tourists, the language barrier was perceived as another risk. As Tayler (1991) noted, the language barrier is one of the main issues that can pose major challenges to tourism destinations and hotels catering to international markets when it comes to providing satisfactory experiences. The language gap in overseas travel has been studied as a constraining factor for intercultural communication (Cohen, 2004), and as an obstacle in learning the local culture (Gmelch, 1997). Researchers have found that the lack of language fluency contributes to tourists' experience in terms of role conflicts, diffidence, and defensiveness when 
travelling overseas (Hottola, 2004). In particular, the language barrier issue has been seen to play a significant role in Chinese outbound tourists' overseas travel and hotel experiences (Xu\&McGehee, 2012). Despite the fact that almost one third of the Chinese population (approximately 400 million) have learnt English, merely 7\% report that they 'often' use the language, compared with $23 \%$ who use it 'sometimes', and 69\% who use it 'seldom' (China Daily, 2010, as cited in Bolton \&Graddol, 2012). Thus the majority of Mainland Chinese still lack sufficient language skills for effective communication in English (Bolton \&Graddol, 2012), and this deficiency could prove a significant issue when these people become outbound tourists. However, despite English being used as an international language, it is seldom spoken by Ukrainian people because Ukrainian people do not have the chance to learn English as a second language during their schooling. So, in the absence of English as a lingua franca, finding a way to communicate with each other is a major problem for both Chinese tourists and local Ukrainian people especially when they have no translators on hand.

Interestingly, despite Ukraine still being in a state of political instability and potential war, Chinese male outbound tourists remain willing to travel to this country. As the interview data reveal, while some respondents hint that there are comparatively high perceived risks in travelling to Ukraine, other equally important factors support their decision to visit this country. As this study demonstrates, seeking an authentic romantic relationship with local women should be emphasised as one major finding of this research. This finding could offer a special angle from which to understand Chinese male outbound tourists more comprehensively and deeply.

\section{REFERENCES}

[1] Baloglu, S. (2001). Image variations of Turkey by familiarity index: Information and experiential dimensions. Tourism Management, 22(2), 127-133.

[2] Baloglu, S., \&McCleary, K. W. (1999).A model of destination image formation.Annals of Tourism Research, 26(4), 868-897.

[3] Beerli, A., \& Martín, J. D. (2004). Factors influencing destination image.Annals of Tourism Research, 31(3), 657-681.

[4] Bolton, K., \&Graddol, D. (2012). English in China today.English Today, 28(3), 3-9.

[5] Carr, N. (2001). An exploratory study of gendered differences in young tourists' perception of danger within London.Tourism Management, 22, 565-570.

[6] Causevic, S., \& Lynch, P. (2013). Political (in)stability and its influence on tourism development. Tourism Management, 34, 145-157.

[7] Chen, C.-F., \& Tsai, D. (2007). How destination image and evaluative factors affect behavioural intentions? Tourism Management, 28(4), 1115-1122.

[8] Cohen, E. (1972). Towards a sociology of international tourism. Sociological Research, 39, 164-182

[9] Cohen, E. (2004). Contemporary tourism: Diversity and change. Boston, MA: Elsevier.

[10] Crompton, J. L. (1979). An assessment of the image of Mexico as a vacation destination and the influence of geographical location upon that image. Journal of Travel Research, 18 (4) 18-23.

[11] Engel, J. F., Blackwell, R. D., \&Miniard, R. W. (1986). Consumer behaviour. Chicago, IL: The Dryden Press.

[12] Faulkner, B. (2001). Towards a framework for tourism disaster management. Tourism Management, 22(2), 135-147.

[13] Gartner, W. C. (1993). Image formation process.Journal of Travel and Tourism Marketing, 2, 191-216.

[14] Gibson, H., \&Yiannakis, A. (2002). Tourist roles: Needs and the lifecourse. Annals of Tourism Research, 29(2), 358-383.

[15] Gmelch, G. (1997). Crossing cultures: Student travel and personal development. International Journal of Intercultural Relations, 21(4), 475-490.

[16] Hottola, P. (2004). Culture confusion: Intercultural adaptation in tourism. Annals of Tourism Research, 31(2), 447-466.

[17] Hall, C. M., \& O'Sullivan, V. (1996). Tourism, political stability and violence. In A. Pizam\& Y. Mansfeld (Eds.), Tourism, crime and international security issues (pp. 105-121). New York, NY: Willey.

[18] Lepp, A., \& Gibson, H. (2008). Sensation seeking and tourism: Tourist role, perception of risk and destination choice. Tourism Management, 29(4), 740-750. 
[19] Lepp, A., \& Gibson, H. (2003). Tourist roles, perceived risk and international tourism.Annals of Tourism Research, 30(3), 606-624.

[20] Lepp, A., Gibson, H., \& Lane, C. (2011). Image and perceived risk: A study of Uganda and its official tourism website. Tourism Management, 32(3), 675-684.

[21] Patton, M. Q. (1990). Qualitative evaluation and research methods (2nd ed.). London: Sage.

[22] Pike, S. (2002). Destination image analysis:a review of 142 papers from 1973 to 2000. Tourism Management, 23, 541-549.

[23] Pike, S., \& Ryan, C. (2004). Destination positioning analysis through a comparison of cognitive, affective, and conative perceptions. Journal of Travel Research, 42(May), 333-342.

[24] Pizam, A., Jeong, G., Reichel, A., Van Boemmel, H., Lusson, J., Steynberg, L., et al. (2004). The relationship between risk taking, sensation seeking and the tourist behaviour of young adults: A cross cultural study. Journal of Travel Research, 42, 251-260.

[25] Qi, C., Gibson, H., \& Zhang, J. (2009). Perceptions of risk and travel intentions: The case of China and the Beijing Olympic Games.Journal of Sport and Tourism, 14(1), 43-67.

[26] Reisinger, Y., \&Mavondo, F. (2005). Travel anxiety and intentions to travel internationally: Implications of travel risk perception. Journal of Travel Research, 43, 212-225.

[27] Roehl, W., \&Fesenmaier, D. (1992). Risk perceptions and pleasure travel: An exploratory analysis. Journal of Travel Research, 2, 17-26.

[28] Russell, J. A., \& Snodgrass, J. (1987). Emotion and environment. In D. Stockols\& I. Altman (Eds.), Handbook of environmental psychology (pp. 245-280).

[29] Sandiford, P., \& Seymour, D. (2007). A discussion of qualitative data analysis in hospitality research with examples from an ethnography of English public houses. International Journal of Hospitality Management, 26(3), 724-742.

[30] Seddighi, H. R., Nuttall, M. W., \&Theocharous, A. L. (2001). Does cultural background of tourists influence the destination choice? An empirical study with special reference to political instability. Tourism Management, 22(2), 181-191.

[31] Sirakaya, E., Sheppard, A., \&McLellan, R. (1997). Assessment of the relationship between perceived safety at a vacation site and destination choice decisions: Extending the behavioural decision-making model. Journal of Hospitality and Tourism Research, 21(2), 1-10.

[32] Sönmez, S. F., \&Graefe, A. R. (1998). Influence of terrorism risk on foreign tourism decisions. Annals of Tourism Research, 25(1), 112-144.

[33] Statista (2016). Facts on the global tourism industry. Retrieved from http://www.statista. com/topics/962/global-tourism/

[34] Steiner, C. (2007). Political instability, transnational tourist companies and destination recovery in the Middle East after 9/11. Tourism and Hospitality Planning and Development, 4(3), 169-190.

[35] Tayler, E. M. (1991). Global hosts need foreign languages. Hotels, 25(10), 17.

[36] Visit Kiev Ukraine (2015). Ukraine Tourism and Visitor Statistics. Retrieved from http://www. visit kievukraine .com/essential/tourism-statistics/

[37] Xinhua (2016). Feature: Chinese tourists, businessmen welcome Ukraine's new visa-on-arrival policy. Retrieved from http://news.xinhuanet.com /english/2016/06/21/ c_135452188. Htm

[38] Xu, Y., \&McGehee, N. G. (2012). Shopping behavior of Chinese tourists visiting the United States: Letting the shoppers do the talking. Tourism Management, 33(2), 427-430.

[39] Yap, G., \&Saha, S. (2013). Do political instability, terrorism, and corruption have deterring effects on tourism development even in the presence of UNESCO heritage? A cross-country panel estimate. Tourism Analysis, 18(5), 587 - 599.

[40] Yu, Y., \& Dean, A. (2001). The contribution of emotional satisfaction to consumer loyalty. International Journal of Service Industry Management, 12(3), 234-250.

\section{AUTHOR'S BIOGRAPHY}

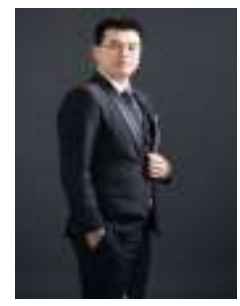

Mr. Jun Wen is currently a $\mathrm{PhD}$ candidate in the Department of Tourism and Hospitality Management, the University of Waikato, New Zealand. His research interest lie in tourist behaviour in the context of special interest tourism including cigar tourism, pet tourism, sex tourism, and drug tourism. He also focuses on consumer behaviour studies from Chinese perspective. 


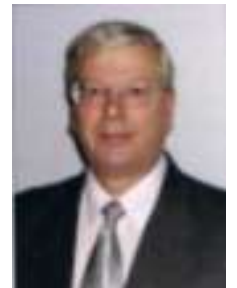

Dr.Tim Lockyer is currently Associate Professor, Department of Tourism and Hospitality Management, Waikato Management School, University of Waikato. In 2007 he published a research book entitled The International Hotel Industry: Sustainable Management. His main interest is tourism and hospitality management and control.

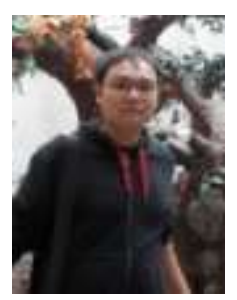

Mr.Hanlin Zhang is interested in academic research in relation to business and management studies in the Chinese context. He is now focusing on tourism studies from Chinese outbound tourists' perspective.

Citation: Jun Wen, Dr. Tim Lockyer, Hanlin Zhang. "Destination Image and Perceived Risk of Visiting Ukraine: An Exploratory Study of Chinese Male Outbound Tourists" International Journal of Research in Tourism and Hospitality (IJRTH), vol 4, no. 1, 2018, pp. 01-09. doi:http://dx.doi.org/10.20431/24550043.0401001 .

Copyright: (c) 2018 Authors. This is an open-access article distributed under the terms of the Creative Commons Attribution License, which permits unrestricted use, distribution, and reproduction in any medium, provided the original author and source are credited. 